\title{
Aquatic Invasive Species Research Capabilities at the Upper Midwest Environmental Sciences Center
}

Aquatic invasive species such as the sea lamprey, zebra mussel, and Asian carps reshape aquatic communities, cost millions annually to manage and control, and threaten the biodiversity of freshwaters. The rate at which invasive species are moved and spread is increasing and detrimental economic and ecological effects continue to mount. Further, natural resource managers have identified invasive species as one of the most serious problems they face in the United States. To address this problem, scientists at the U.S. Geological Survey Upper Midwest Environmental Sciences Center (UMESC) are refocusing their research efforts on aquatic invasive species based on UMESC personnel, facility assets, and resource management needs.

Aquatic invasive species like the sea lamprey have been studied at UMESC since the 1950s. One notable research assignment early in the Center's history was to develop chemical controls for sea lamprey- primitive parasitic fish that attach to other fishes with a suction disc to live on the host's blood and body fluids. This research, conducted in cooperation with the Great Lakes Fishery Commission, helped greatly reduce populations of sea lamprey in the Great Lakes. Since the 1990s, UMESC scientists have extended their expertise in chemical control to newly established nonnative species in the Great Lakes and conducted ecological research on the effects of zebra mussels and Asian carps.

\section{UMESC Strategic Plan for Research on Aquatic Invasive Species (AIS) Highlights}

\section{(1) Preventing the Introduction of AIS}

Develop tools for managers to prevent the introduction of AIS in the United States

(2) Early Detection, Rapid Response, and Spread of AIS Provide science support for resource managers to eradicate newly reported AIS and to predict their potential spread

\section{(3) Science Support for Monitoring AIS}

Improve and refine methods used by managers to monitor expanding populations of AIS in the Upper Mississippi River

\section{(4) Ecology and Effects of AIS}

Study the ecology of AIS to identify and quantify the effects of harmful AIS on native ecosystems and their components

\section{(5) Control and Management of Existing AIS}

Work with managers to develop and improve alternatives for controlling AIS to restore native species and ecosystem function

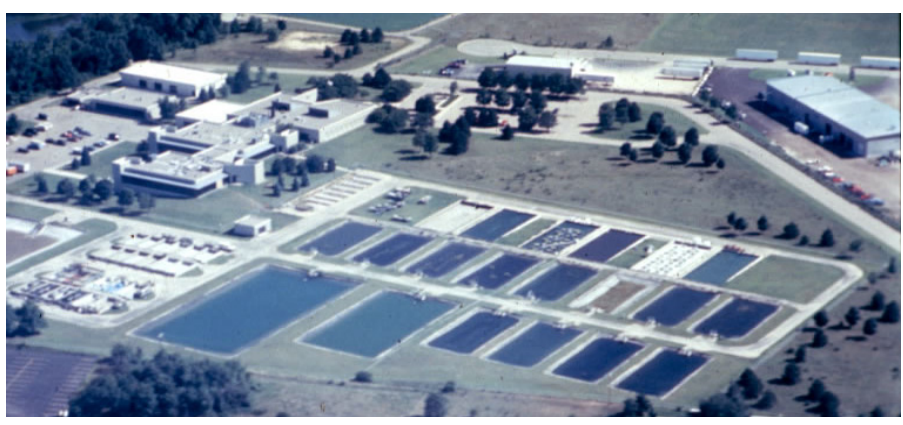

The USGS Upper Midwest Environmental Sciences Center in La Crosse, Wisconsin, showing a variety of ponds used for culture and experimentation.

\section{Selected Projects}

\section{Asian carp control investigations}

The threat of Asian carp entering the Great Lakes at Lake Michigan through the Chicago Sanitary and Shipping Canal has increased the urgency of finding ways of controlling these aquatic invaders. USGS has received funding from the US Environmental Protection Agency Great Lakes Restoration Initiative to develop new chemicals and new delivery technologies aimed at control of silver and bighead carps. The UMESC is collaborating with the USGS Columbia Environmental Research Center to develop chemical, physical, and biological means of controlling the carps to limit or prevent the spread of these fish throughout the Great Lakes basin.

\section{Technical assistance to Great Lakes sea lamprey control program}

As part of our commitment to provide technical assistance to the Great Lakes Fishery Commission's Sea Lamprey Control Program, we conduct risk assessments of lampricide treatments on nontarget species of concern. Scheduled sea lamprey stream treatments were allowed based on our recent findings demonstrating minimal risk of lampricides to three species of native mussels classified as threatened, endangered, or of special concern by the State of Vermont. Data were provided that helped support a risk assessment for piping plovers, an endangered avian species which inhabits a limited number of streams in the Great Lakes basin. We are currently engaged in collaborative research to determine the impacts of lampricide treatments on lake sturgeon, mudpuppies, stonecats, and snuffbox mussels. 


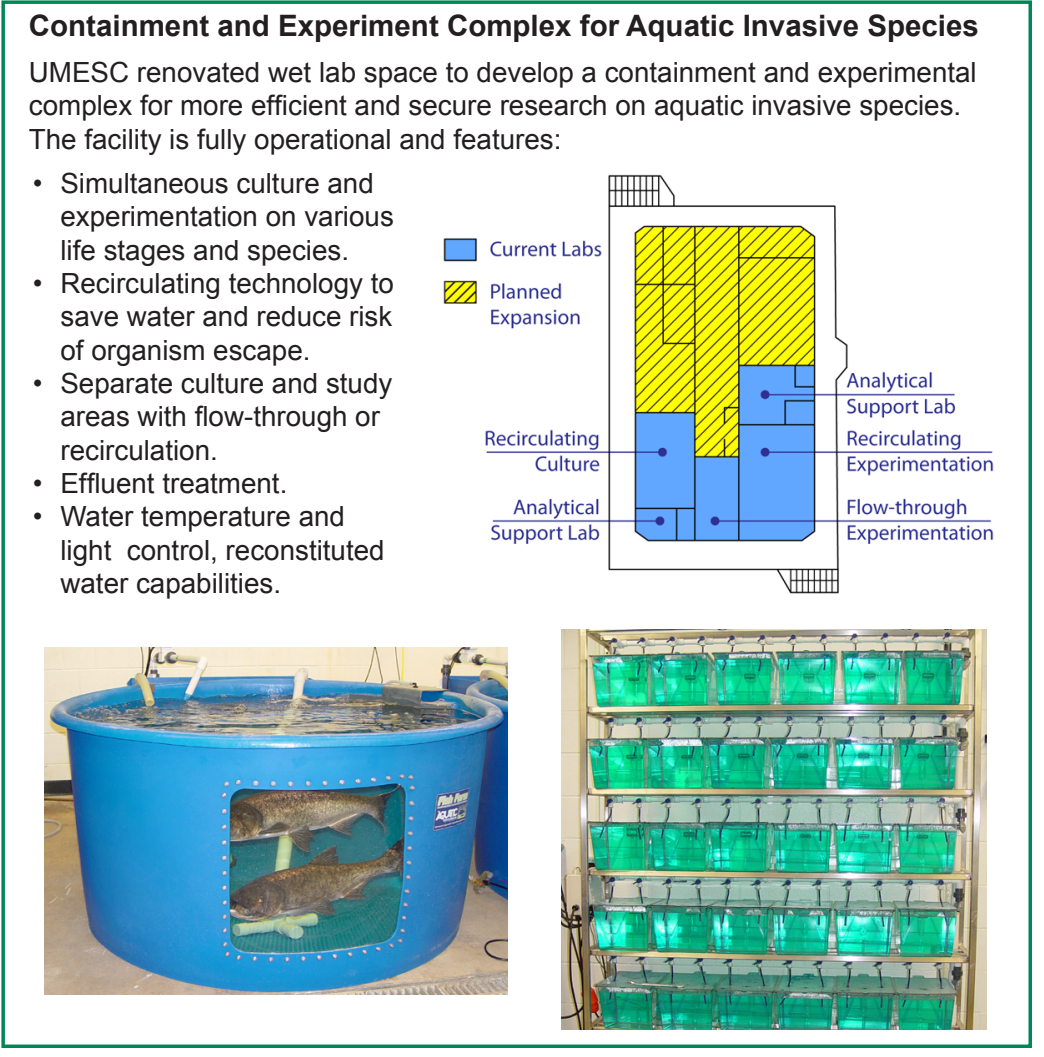

Integrated pest management of nonnative fishes in the southwestern United States

The Bureau of Reclamation identified the need to control invasive fishes in the southwestern United States to protect native species. The UMESC reviewed taxon-specific piscicides and other management options for controlling nonnative fish. The report focuses on the feasibility of developing piscicides (chemicals to control unwanted fish) selective for specific groups of fishes and suggests developing an integrated management program that combines the use of chemicals with other control techniques such as barriers, selective removal, and habitat alteration. The UMESC is currently engaged in planning research to address this problem collaboratively with the Bureau of Reclamation.

\section{UMESC Assets and Capabilities for Research on Aquatic Invasive Species}

- Containment and experimental complex for experimentation with aquatic invasive species with recirculating and flow-through capabilities

- Unique facilities, including onsite culture and analytical laboratories and experimental ponds
- Expertise in the development of methods for the analysis of residues of fishery management chemicals in tissues, sediment, and water.

- Extensive experience in evaluation of the efficacy, safety, and environmental effects of fishery management chemicals

- Expertise in regulatory affairs with U.S. EPA, Health Canada, and state natural resource and environmental agencies

- Monitoring expertise from 20 years of experience with the Long Term Resource Monitoring Program

- Over 50 years of partnering with the Great Lakes Fishery Commission in support of the Sea Lamprey Control Program in the Great Lakes basin

- Capacity to integrate work and develop innovative decision support systems

- Strategically located between the Mississippi River and Great Lakes basins, two of the most utilized watersheds in the world

\section{Dedicated Research Staff}

Terrance Hubert, Ph.D. Chemist: Pheromones, analytical chemistry, integrated pest management, regulatory affairs

Mark Gaikowski, M.A. Supervisory Biologist: Toxicity and environmental studies, delivery technologies

Jon Amberg, Ph.D. Fish Biologist: Genetic, physiology and toxicity studies, delivery technologies, nanotechnology

Jeff Bernardy, M.S. Chemist: Analytical chemistry, residue depletion and environmental studies

Michael Boogaard, M.S. Biologist: Toxicity studies, rapid response and integrated pest management

James Luoma, B.S. Fish Biologist: Toxicity studies, integrated pest management, delivery technologies

Jane Rivera, B.S. Biologist: Acting Quality Assurance Officer, regulatory affairs, toxicity studies

Theresa Schreier, B.S. Biologist: Analytical chemistry, residue depletion, toxicity and environmental studies

Visit the UMESC website at http://www.umesc.usgs.gov for information on UMESC projects, scientific publications and other products, staff profiles, and other useful information.

For more information, contact

Terrance D. Hubert

U.S. Geological Survey

Upper Midwest Environmental Sciences Center

2360 Fanta Reed Road

La Crosse, Wisconsin 54603

608.781 .6227

thubert@usgs.gov 